\title{
Predação de frutos e de lagartas artificiais como proposta de atividade prática para o ensino de ciências
}

\section{Predation of artificial fruits and caterpillars as practice activity proposed to science classes}

\author{
${ }^{1}$ Maria Carolina Brunini Siviero \\ ${ }^{1}$ Nidia Mara Marchiori nidiamarchiori@yahoo.com.br \\ ${ }^{1}$ Lara Priscila Domingues Cazotto \\ ${ }^{1}$ Marina Dal’Bó Pelegrini \\ ${ }^{1}$ Carolina Stefano Mantovani \\ ${ }^{1}$ Karina Rebelo Elisiário de Almeida \\ ${ }^{1}$ Eleonore Zulnara Freire Setz
}

\section{RESUMO}

Aulas de Ciências incorporam uma motivação natural pelas vivências práticas que conduzem à investigação dos diversos aspectos da natureza. As atividades práticas contribuem para aproximar o conhecimento com as experiências vividas, além de despertar a curiosidade e o sentimento crítico. No entanto, a aplicação dessas atividades também envolve as condições de infraestrutura da escola e da própria dinâmica do experimento, idealmente optando por materiais acessíveis e não restritivos a grupos etários para maior viabilidade e visibilidade. Assim, propomos um experimento de Ciências sobre predação de frutos e de lagartas artificiais utilizando massa de modelar a base de cera. Buscamos sugerir uma alternativa prática de fácil obtenção e manipulação e com variada possibilidade didática.

Palavras-chave: Experimento de zoologia. Relações ecológicas. Massa de modelar.

\section{ABSTRACT}

Science classes are a natural motivation for practical experiences that lead to investigation of various aspects of nature. Practical activities contribute to approach the knowledge with the lived experiences, for the awakening of curiosity and critical feeling. However the application of practical activities also involves conditions of school infrastructure and the dynamics of experimental activity, ideally choosing for materias with easy access and not restricted to specific groups. Considering these aspects, we propose a Sciences experiment about predation of artificial fruits and caterpillars using modeling clay on the wax base. The proposed activity makes use of material with easy obtain and handling, also this allows a variety of locations for its realization.

Keywords: zoology experiment. Ecological interactions. Modeling clay.

1 Instituto de Biologia, Universidade Estadual de Campinas, São Paulo, Brasil. 


\section{INTRODUÇÃO}

Tendo como base o saber necessário à prática educativa trazido por Freire (2009) de que ensinar não se trata de uma simples transferência de conhecimento, mas de se criar possibilidades para a sua própria construção, entende-se que o processo educativo deve caminhar de forma a favorecer a aptidão natural da mente em formular questionamentos e resolver problemas. Como destaca Moreira (1993, p. 50), “o trabalho em sala de aula precisa abrir-se para uma pluralidade de métodos e de linguagens, visando a favorecer ao aluno a aquisição de processos variados de construção de conhecimento, comunicação e de expressão.” Nesse sentido, as atividades práticas contribuem como instrumento metodológico que possibilita aos alunos se situarem numa perspectiva de vivenciar o ensino, de refletirem sobre seus próprios conhecimentos conectando-os aos novos conhecimentos testemunhados.

Aspectos relacionados às atividades práticas no ensino de Ciências envolvem, por exemplo, o conhecimento de fenômenos naturais através de novas experiências que facilitem um contato com a natureza e com o fenômeno estudado, o desenvolvimento de habilidades científicas práticas como a observação e a manipulação, a possibilidade da exploração, de testar ideias através da busca de alternativas experimentais e da comprovação da teoria através da experimentação (MIGUENS; GARRET, 1991).

Nas aulas de Ciências há uma motivação natural por essas vivências práticas que conduzem a investigações sobre diversos aspectos da natureza, tornado-as cercadas de expectativa por parte dos alunos (BIZZO, 2000). As atividades práticas investigativas são um ponto de partida para desenvolver a compreensão de conceitos, oferecendo ao aluno a oportunidade de perceber e agir sobre o objeto de estudo, relacionando o objeto com acontecimentos e buscando as causas dessa relação (AZEVEDO, 2004).

No entanto, conforme Bizzo (2000), o esforço dos alunos não deve ser canalizado unicamente para apresentar o resultado esperado pelo professor, mas para desvendar os significados presentes naquele conhecimento. Ou seja, para que o verdadeiro aprendizado de Ciências não se reduza a uma mera coleção de saberes descontextualizados, a construção do conhecimento deve passar pela interação de conceitos e funcionalidades (INSAUSTI; MERINO, 2000). Nesse sentido, o produto da investigação passa a ser um ponto de partida para a contextualização do conhecimento.

Além disso, também é preciso considerar que tão importante quanto o produto, é o processo da construção do conhecimento pelos alunos, o qual envolverá o uso de suas estruturas mentais, suas habilidades e suas emoções (AZEVEDO, 2004). Nesse sentido, o exercício da curiosidade, que Freire (2009, p. 88) destaca como sendo aquele que "convoca a imaginação, a intuição, as emoções, a capacidade de conjecturar, de comparar" é um fator importante a ser valorizado na atividade prática. Estimulando a curiosidade através do processo investigativo, o aluno deixa de ser apenas um observador das aulas e, ao passo que argumenta, pensa, age e questiona, passa a ser autor na construção do seu conhecimento (AZEVEDO, 2004).

Outro aspecto importante das atividades práticas envolve sua adequação à realidade dos alunos, às condições de infraestutura e a própria dinâmica da atividade experimental (VASCONCELOS; SOUTO, 2003). Experimentos com material acessível e que não se restrinjam a um local específico, podem apresentar uma viabilidade fundamental para a sua realização. A utilização de massa de modelar, por exemplo, é uma opção acessível para atividades práticas. Simulando frutos e lagartas com este material é possível abordar conteúdos de zoologia e ecologia (veja, por exemplo, CHAVES, 1998; ALVES-COSTA; LOPES, 2001; GALETTI; ALVES-COSTA; CAZETTA, 2003; ARRUDA; RODRIGUES; IZZO, 2008).

Considerando todos os aspectos abordados, vê-se de grande importância a proposição de atividades práticas que, além de naturalmente incentivarem a investigação e a interpretação, levem em conta a viabilidade da execução objetivando abranger diferentes realidades escolares. Assim, objetivamos propor uma atividade prática 
de simples elaboração para a abordagem de conceitos zoológicos e ecológicos através de experimentos de predação de frutos e de lagartas artificiais.

\section{PROCEDIMENTOS METODOLÓGICOS}

Vinte e um conjuntos de massa de modelar atóxica a base de cera foram utilizados para a confecção dos frutos e das lagartas artificiais. Este material foi distribuído para um igual número de alunos de uma disciplina de licenciatura em Ciências Biológicas que confeccionaram os modelos de frutos utilizando as cores amarelo, azul e vermelho, e os modelos de lagartas com as cores branco, marrom e verde (para que o material seja totalmente aproveitado, sugere-se que as cores escolhidas para a confecção dos modelos estejam contidas no mesmo conjunto de massa de modelar). Os frutos e as lagartas artificiais foram dispostos em áreas de vegetação na Universidade Estadual de Campinas, em quintais, em jardins, em praças públicas, em sítios e em pomares.

\section{1 Experimento 1: Predação de frutos artificiais}

As unidades de massa de modelar amarela, azul e vermelha dos 21 conjuntos foram divididas em oito subunidades de um $1 \mathrm{~cm}$ e com cada uma destas subunidades foi modelado um fruto esférico, obtendo-se 168 frutos de cada cor e um total de 504 frutos (24 frutos por aluno). Estes frutos foram agrupados em pares de mesma cor ligados por um barbante de $2 \mathrm{~cm}$ (cada ponta do barbante ficou inserida dentro de um fruto) e pendurados em mais de uma árvore, próximo às extremidades dos galhos para facilitar a visualização pelas aves. Também é possível utilizar linha de costura ou aproveitar-se das bifurcações nos galhos para apoiar os frutos. Os modelos ficaram expostos por sete dias (Figura 1).

Figura 1.- Desenho esquemático da confecção dos frutos artificiais. (a) Unidade de massa de modelar exemplificada pela cor vermelha; (b) Exemplo de frutos artificiais modelados com duas das oito subunidades; (c) Formação de um par de frutos artificiais interligados por barbante; (d) Exemplos de disposição dos frutos artificiais.
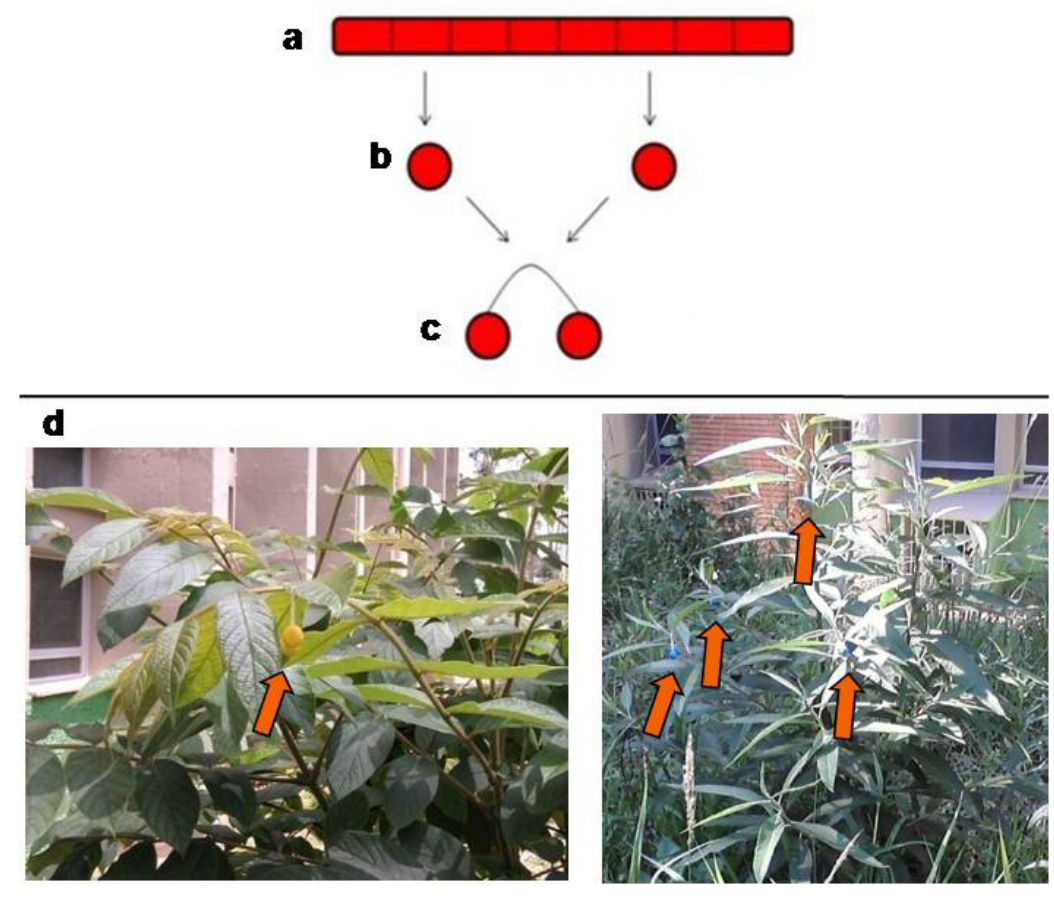


\section{2 Experimento 2: Predação de lagartas artificiais}

As unidades de massa de modelar branca, marrom e verde dos 21 conjuntos foram divididas em oito subunidades e, de cada subunidade, duas lagartas foram modeladas com $3 \mathrm{~cm}$ de comprimento e $0,5 \mathrm{~cm}$ de diâmetro, aproximadamente, obtendo-se 336 lagartas de cada cor e um total de 1008 lagartas (48 lagartas por aluno). Alguns modelos foram colados na nervura central das folhas com cola branca e outros, somente virando a ponta da massa de modelar e enganchando-a na folha. Também é possível fixar com cola a base de farinha e cola de madeira. Depois de sete dias expostas, as lagartas foram removidas para serem analisadas as marcas de predação (Figura 2).

Figura 2.- Desenho esquemático da confecção das lagartas artificiais. (a) Exemplo de confeç̧ão de quatro lagartas de cada cor a partir de 2 subunidades; (b) Exemplos de disposição das lagartas artificiais na vegetação.

a
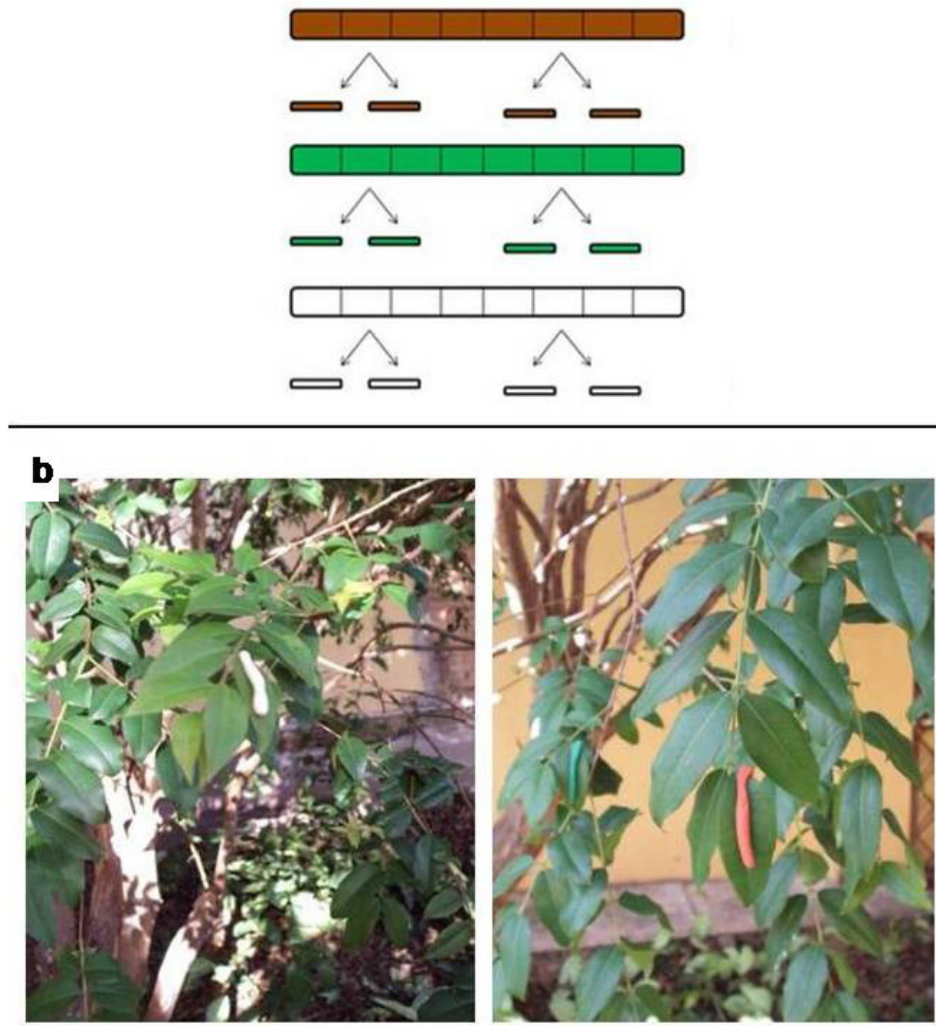

No recolhimento dos experimentos os frutos e as lagartas artificiais foram retirados com cuidado para que não houvesse marcas de unha ou amassados que pudessem interferir na análise das marcas de predação. Uma alternativa para que os fios que unem os frutos não se emaranhem é a utilização de um cabide durante o recolhimento. É interessante que sejam fotografados os locais de realização dos experimentos e as marcas de predação para serem socializados e comparados.

\section{RESULTADOS E DISCUSSÃO}

A proposta da atividade para o ensino de Ciências sobre predação dos frutos e das lagartas artificiais foi elaborada com material de fácil obtenção e permitiu sua execução em diversos locais, oferecendo assim uma forma criativa de abordar, especialmente, os conteúdos zoológicos e ecológicos envolvidos. 
No experimento dos frutos artificiais 122 foram bicados. Os frutos de cor vermelha corresponderam a 48\% deste total, seguido pelos de cor azul (27\%) e amarelo (25\%) (Figura 3). Neste caso, nota-se uma seleção dos frutos vermelhos pelas aves, cuja orientação visual é bem desenvolvida: quanto mais conspícua for a cor de um fruto, com mais facilidade ele será visualizado e, provavelmente, dispersado. Em outros experimentos com frutos artificiais (ALVES-COSTA; LOPES, 2001; GALETTI; ALVES-COSTA; CAZETTA, 2003; ARRUDA; RODRIGUES; IZZO, 2008; AGUIAR, 2009; CARVALHO et al., 2009) os de coloração vermelha também estiveram entre os mais bicados. Diante disso, sugerimos que a cor vermelha esteja entre as cores de massa de modelar escolhidas para a confecção dos frutos, estimulando investigações sobre este aspecto. Embora a cor preta não tenha sido testada neste experimento, frutos modelados com esta cor também se destacam entre os mais predados (ALVES-COSTA; LOPES, 2001; GALETTI; ALVES-COSTA; CAZETTA, 2003; CARVALHO et al.,2009).

\section{Figura 3.- Marcas de bicada nos frutos artificiais.}
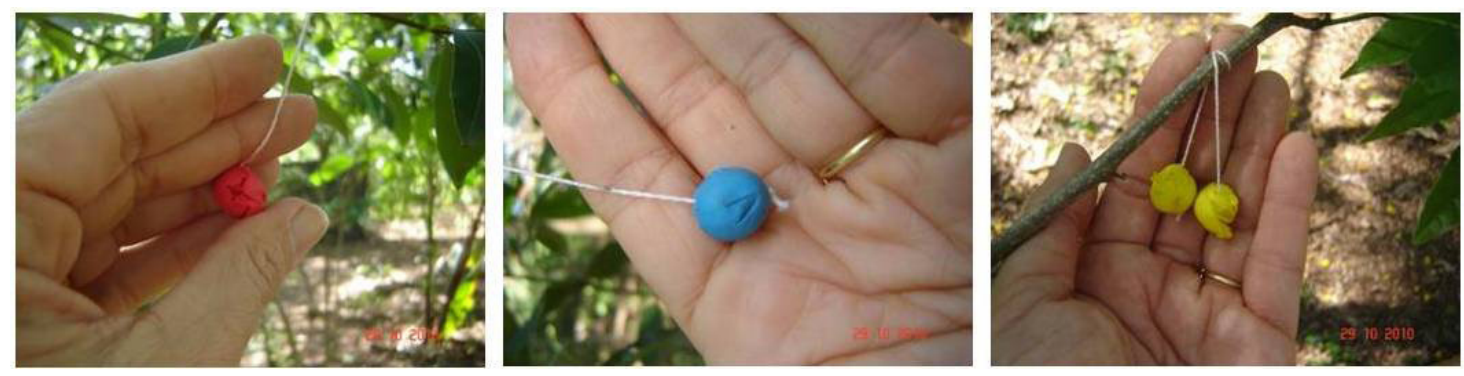

Observando o nível de ensino - fundamental ou médio - a atividade permite abordar outros fatores os quais, associados à conspicuidade, podem influenciar a predação dos frutos artificiais. Entre eles, o tipo de ecossistema ao redor, a estação com maior ou menor oferta de frutos verdadeiros (ALVES-COSTA; LOPES, 2001), a disposição dos modelos artificiais (borda/interior de um fragmento) e o tamanho do fragmento (GALETTI; ALVES-COSTA; CAZETTA, 2003).

No experimento das lagartas artificiais 70 apresentaram marca de predação, assemelhando-se entre as três cores: branco (39\%), verde (33\%) e marrom (28\%) (Figura 4). As lagartas tendem a apresentar coloração críptica, ou seja, assemelhar-se ao substrato para evitar as aves, dessa forma, a coloração parece não ser o fator determinante para a predação. Outra informação visual parece ser utilizada pelos predadores, como sinais de herbivoria na planta. Chaves (1998) verificou que lagartas colocadas em folhas com sinais de herbivoria receberam mais ataques do que aquelas localizadas em folhas que não transmitiam esta informação visual. Diante disso, sugere-se que para aumentar as chances de predação, lagartas sejam colocadas em folhas com estas características ou até mesmo divididas entre folhas com e sem sinal de herbivoria para propiciar comparações. A colocação de lagartas artificiais em vegetação com compostos voláteis também poderia aumentar as chances de predação por serem atrativos às vespas, outros predadores das lagartas.

Figura 4.- Marcas de predação nas lagartas artificiais.
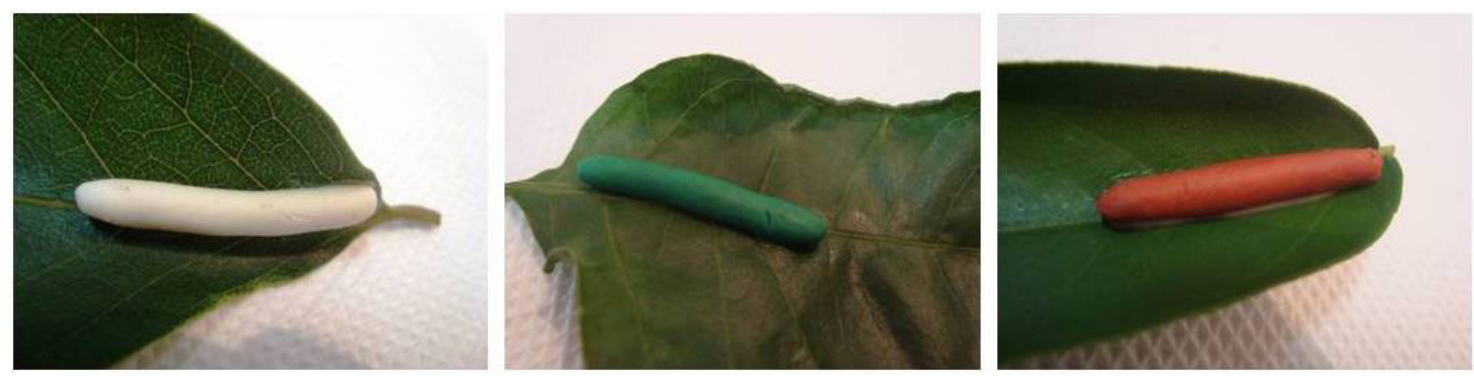
A baixa porcentagem de predação das lagartas artificiais (7\%) foi diretamente influenciada pelo vento, pela chuva e pela remoção por pessoas. Não foi possível encontrar lagartas que caíram em solo coberto por folhas, inclusive não indicamos o revolvimento desses locais por serem abrigo de animais que podem oferecer risco.

Embora a remoção dos frutos e das lagartas artificiais também possa ser realizada pelas próprias aves, observamos que muitas das remoções ocorreram por crianças, gatos, cachorros, podas e pessoas desinformadas da realização do experimento, além da chuva e do vento. Diante disso, alertamos para a previsão destes fatores durante a escolha dos locais, além de uma boa fixação dos modelos artificiais na vegetação, evitando perdas que prejudicarão os experimentos.

A proposição destes experimentos, enquanto atividade prática investigativa, tem como ponto chave o estímulo da curiosidade nos alunos, que assim como considera Freire (2009), conduz a um ambiente favorável à produção do conhecimento. Para tanto, também é de fundamental importância o papel do professor motivando a observação, lançando questionamentos e salientando aspectos importantes a serem cogitados na investigação. Ademais, tão importante quanto, é incentivar os alunos a pensarem sobre os temas tratados e reconhecer suas conquistas em seu processo de aprendizagem (BIZZO, 2000).

Como ponto de partida para os temas, sugerimos uma abordagem a respeito das cores que, ao passo que nos frutos devem atrair as aves para a dispersão das sementes, nas lagartas devem torná-las crípticas para evitar sua captura pelas aves. Mais amplamente, são possíveis abordagens sobre regeneração de florestas, formato do bico, outros animais dispersores de frutos, outras formas de dispersão, controle biológico e estratégias antipredação das lagartas (p. ex.: colorações de advertência e presença de cerdas), favorecendo o processo de contextualização de saberes.

Por certo, através das atividades práticas o aluno tem a oportunidade de "aprender ciência e aprender a fazer ciência” (INSAUSTI; MERINO, 2000). E, através de simples experimentos, perceber que o conhecimento científico não se limita a laboratórios sofisticados, mas pode ser construído em vários espaços, em parceria com professores e colegas (VASCONCELOS; SOUTO, 2003).

Enfim, considerando todos esses aspectos, os experimentos propostos se oferecem como atividades colaborativas para o ensino-aprendizagem de Ciências que, enquanto disciplina naturalmente investigativa, deve favorecer um despertar de inquietações como o primeiro passo para a construção de um caminho de investigações e descobertas.

\section{CONSIDERAÇÕES FINAIS}

- Os experimentos de predação de frutos e de lagartas artificiais são atividades práticas de elaboração simples, realizáveis com material de fácil obtenção e que permitem uma variedade de locais possíveis para a execução, sendo interessantes instrumentos para abordagem de conteúdo zoológico e ecológico.

- Para uma melhor execução da atividade devem ser previstos fatores como chuva e passagem de pessoas e de animais domésticos pelo local.

- A abordagem principal sobre dispersão de sementes e predação de lagartas pode ser ampliada e conectada com questões mais complexas, visto que a mesma atividade pode ser realizada no ensino fundamental e médio, adequando a abordagem dos conceitos ao nível correspondente. 


\section{AGRADECIMENTOS}

Agradecemos pela participação nos experimentos aos alunos da disciplina “Tópicos Especiais em Ecologia” oferecida em 2010 no Instituto de Biologia da UNICAMP. 


\section{REFERÊNCIAS BIBLIOGRÁFICAS}

AGUIAR, A. G. de. Efeitos da coloração e distribuição de frutos artificiais nas taxas de consumo por aves no Parque Estadual da Cabeça do Cachorro, São Pedro do Iguaçu - Paraná. Monografia (Graduação em Ciências Biológicas), Pontifícia Universidade Católica do Paraná, PUCPR, Toledo. 2009

ALVES-COSTA, C. P.; LOPES, A. V. Using artificial fruits to evaluate fruit selection by birds in the field. Biotropica, v. 33(4), p. 713-717. 2001.

ARRUDA, R.; RODRIGUES, J. D.; IZZO, T. J. Rapid assessment of fruit-color selection by birds using artificial fruits at local scale in Central Amazonia. Acta Amazonica, v. 38(2), p. 291-296. 2008.

AZEVEDO, M. C. P. S. de. Ensino por investigação: problematizando as atividades em sala de aula. In: A.M.P. de Carvalho (Org.), Ensino de Ciências: unindo a pesquisa e a prática. São Paulo: Pioneira Thomson Learning. p. 19-33. 2004.

BIZZO, N. Ciências: fácil ou difícil? 2. ed. São Paulo: Ática. 2000.

CARVALHO, D. P.; AOKI, C.; SOUZA, F. L.; MONTANHEZ, B. E.; OLIVEIRA, L. V.; RECH, R. Utilização de frutos artificiais no teste de preferência das aves por tamanho, cor e estrato de distribuição de frutos em remanescente de cerrado em Campo Grande, Mato Grosso do Sul. In: Anais $9^{\circ}$ Congresso de Ecologia do Brasil. Sociedade de Ecologia do Brasil. São Lourenço, Minas Gerais - Brasil. Em: http://www.seb-ecologia. org.br/2009/resumos_ixceb/780.pdf. 2009.

CHAVES, G. W. A influência de características morfológicas e comportamentais de lagartas no ataque de predadores: um estudo experimental com larvas artificiais. Dissertação (Mestrado em Ecologia), Instituto de Biologia, Universidade Estadual de Campinas, UNICAMP, Campinas. 1998.

FREIRE. P. Pedagogia da autonomia: saberes necessários à prática educativa. 39. ed. São Paulo: Paz e Terra. 2009.

GALETTI, M.; ALVES-COSTA, C.P.; CAZETTA, E. Effects of forest fragmentation, anthropogenic edges and fruit colour on the consumption of ornithocoric fruits. Biological Conservation, v.111, p. 269-273. 2003.

INSAUSTI, M. J.; MERINO, M. Una propuesta para el aprendizaje de contenidos procedimentales en el labotarorio de Física y Química. Investigações em Ensino de Ciências, v.5(2), p.93-119. 2000.

MIGUENS, M.; GARRET, R. M. Prácticas en la enseñanza de las Ciencias. Problemas y posibilidades. Enseñanza de las Ciencias, v.9(3), p.229-236. 1991. Em: http://ddd.uab.cat/pub/edlc/02124521v9n3p229.pdf

MOREIRA, A. F. B. Conhecimento, currículo e ensino: questões e perspectivas. Revista Em Aberto, v. 12(58), p. 45-53. 1993.

VASCONCELOS, S. D.; SOUTO, E. Livro didático de Ciências no ensino Fundamental - proposta de critérios para análise do conteúdo zoológico. Ciência e Educação, v. 9(1), p.93-104. 2003. 